\title{
Role of the Ubiquitin System in Chronic Pain
}

\author{
Jiurong Cheng, Yingdong Deng and Jun Zhou* \\ Department of Anesthesiology, The Third Affiliated Hospital of Southern Medical University, Guangzhou, China
}

As a significant public health issue, chronic pain, mainly neuropathic pain (NP) and inflammatory pain, has a severe impact. The underlying mechanisms of chronic pain are enigmatic at present. The roles of ubiquitin have been demonstrated in various physiological and pathological conditions and underscore its potential as therapeutic targets. The dysfunction of the component of the ubiquitin system that occurs during chronic pain is rapidly being discovered. These results provide insight into potential molecular mechanisms of chronic pain. Chronic pain is regulated by ubiquitination, SUMOylation, ubiquitin ligase, and deubiquitinating enzyme (DUB), etc. Insight into the mechanism of the ubiquitin system regulating chronic pain might contribute to relevant therapeutic targets and the development of novel analgesics.

\section{OPEN ACCESS}

Edited by:

Xiaodong Liu,

The Chinese University of Hong Kong,

China

Reviewed by:

Shenglan Wang,

Beijing University of Chinese

Medicine, China

Huarong Chen,

The Chinese University of Hong Kong,

China

*Correspondence:

Jun Zhou

zhoujun7843@126.com

Specialty section:

This article was submitted to Pain Mechanisms and Modulators, a section of the journal

Frontiers in Molecular Neuroscience

Received: 02 March 2021 Accepted: 12 April 2021

Published: 28 May 2021

Citation:

Cheng J, Deng Y and Zhou J (2021) Role of the Ubiquitin System

in Chronic Pain.

Front. Mol. Neurosci. 14:674914. doi: 10.3389/fnmol.2021.674914

\section{INTRODUCTION}

Chronic pain is a compounded problem that lasts or recurs for more than 3 months, which significantly affects physical and psychological health (Treede et al., 2019). It is known that chronic pain can result from many pain syndromes. However, the mechanisms underlying chronic pain are complex and not clarified. Therefore, despite a major long-standing investigation for years, there are no effective therapies for most types of chronic pain. Several recent studies have found that ubiquitin system failure is implicated in chronic pain (Tai and Schuman, 2008), mainly including neuropathic pain (NP) and inflammatory pain (Chen et al., 2011). NP is the pain caused by a lesion or somatosensory system disease (Jensen et al., 2011). Inflammatory pain is caused by an increase in the excitability of peripheral nociceptive fibers due to changes in ion channel activity caused by inflammatory mediators (Linley et al., 2010). During the inflammatory process, the pain is triggered by normally innocuous stimuli and becomes chronic if the inflammation is not resolved. The mechanisms of NP are partly distinct from those of inflammatory pain, and potential therapeutic targets mediated by the ubiquitin system to NP and inflammatory pain are different.

The ubiquitin system is a protein degradation pathway mainly composed of ubiquitin, E1 ubiquitin-activating enzyme, E2 ubiquitin-conjugating enzyme, E3 ubiquitin ligase, deubiquitinating enzyme (DUB), and proteasome, etc. The ubiquitination of proteins is a multistep. First, the E1 activates ubiquitin, which is then transferred to E2. Subsequently, the $\mathrm{E} 2 \sim \mathrm{Ub}$ subsequently interacts with E3. And then, the E3 ligase transfers the E2-bound ubiquitin to a substrate and mediates the ubiquitination (Pickart, 2001). Interaction with the substrate can be direct or via ancillary proteins (Glickman and Ciechanover, 2002), finally leading to the degradation of these substrates by proteasomes. Besides, ubiquitination can be antagonized by DUBs, which remove or trim ubiquitin chains on their substrates (Nakamura, 2018). In addition, studies indicate that the ubiquitin-proteasome system (UPS) influences disease onset and progress 
through the timely degradation of various regulatory proteins (Yi and Ehlers, 2007). Hence, a comprehensive understanding of how the ubiquitin system affects chronic pain might be essential for novel therapeutic opportunities for patients.

\section{UBIQUITINATION IN ANIMAL MODELS OF CHRONIC PAIN}

The pathogenesis of chronic pain involves many different mechanisms and the etiology is multifactorial. Thus, animal models are essential for exploring molecular mechanisms of chronic pain. Peripheral or central nerve injury is commonly used to induce NP. The common models of NP include spinal nerve ligation (SNL) model, sciatic nerve chronic constriction injury (CCI) model, and spared nerve injury (SNI) model (Kumar et al., 2018), while the formalin-induced and complete Freund's adjuvant (CFA)-induced models are common in inflammatory pain (Muley et al., 2016). Reliable animal models can help understand the mechanisms of the ubiquitin system in chronic pain to develop effective therapeutics.

It is possible that the chronic pain observed in various rodent pain models could be due to an altered ubiquitin system function. Recent studies investigated the expression and function of E3 ubiquitin ligase, deubiquitinase ubiquitin-specific protease 5 (USP5), and Cav3.2 interaction in CCI-triggered NP (GarcíaCaballero et al., 2014). The researchers study the influence of protein ubiquitination on the development of NP and determine mechanical nociception in the pathophysiological processes of NP using a well-characterized rat model of SNL (Lin et al., 2015; Lai et al., 2016, 2018; Liu et al., 2019). SUMOylation disorder after the injury of peripheral nerves, caused by SNI, may alter the Cav3.2 channel activity (Garcia-Caballero et al., 2019; Liu et al., 2019; Tomita et al., 2019). Both formalin and CFA-induced models are valuable experimental methods for inflammatory pain, which provides an empirical basis for understanding the mechanism of the ubiquitin system on inflammatory pain. Altogether, these data indicate that the ubiquitin system is a major determinant of pain response in both inflammatory pain and NP models. Common ubiquitination in animal models of chronic pain is shown in Table $\mathbf{1}$.

\section{ROLE OF THE UBIQUITIN SYSTEM IN NEUROPATHIC PAIN}

\section{Mechanism of Ubiquitination in Neuropathic Pain}

Protein ubiquitination plays a crucial role in the development of NP (Lai et al., 2016). This function is achieved by ubiquitinationmodified protein receptors and ion channels to affect synaptic activity and efficiency.

NP associated with ubiquitination partly works by regulating signal transduction pathways. The transient receptor potential vanilloid-1 (TRPV1), a member of the transient receptor potential (TRP) family, is considered a therapeutic target for pain relief (Caterina et al., 1997). TRPV1 promotes the ubiquitination of epidermal growth factor receptor (EGFR) in cells and regulates EGFR/mitogen-activated protein kinase (MAPK) signaling through the lysosomal degradation pathway, leading to increased cytoplasmic translocation and degradation of EGFR, and then downregulation of EGFR level. It responds to harmful stimuli from afferent nerve terminals and participates in pain and inflammation (Huang et al., 2020). Lysine ubiquitination is a signal for the transport and degradation of $G$ protein-coupled receptors. Short-term stimulation of substance $P(S P)$ can induce the endocytosis and circulation of the neurokinin-1 receptor (NK1R). Chronic stimulation of SP induces the ubiquitination of lysine residues in NK1R cells, which mediates its degradation and downregulation. In this process, tachykinin is released continuously and prevents nociceptive signals (Cottrell et al., 2006). In addition, tumor necrosis factor-alpha (TNF- $\alpha$ ) influences the development of NP through the ring finger protein (RNF20)/histone H2B monoubiquitination (H2Bub)/RNA polymerase II (pRNAPII)/metabotropic glutamate receptors (mGluR5) signal transduction cascade. Specifically, TNF- $\alpha-$ induced RNF20-driven $\mathrm{H} 2 \mathrm{~B}$ monoubiquitination can promote dorsal horn phosphorylated RNAPII-dependent mGluR5 transcription, affecting protein ubiquitination and degradation (Lai et al., 2016). Tumor necrosis factor receptor-associated factor 2 (TRAF2) and NcK-interacting kinase (TNIK) are enhanced, and the TNIK is coupled to glutamate receptor (GluR1) after nerve injury. TRAF2 is regulated by F-box protein 3 (Fbxo3) and ubiquitination of leucine-rich repeat protein 2 (Fbxl2). Thus, Fbxo3-dependent Fbxl2 ubiquitination and degradation participate in the development of NP by upregulating TRAF2/TNIK/GluR1 signaling (Lin et al., 2015). Studies have demonstrated that TRAF6 has E3 ligase activity; the inhibition of TRAF6 expression can effectively relieve SNL-induced NP. Taken together, the results suggest that TRAF6 serves an important role in NP progression and pathogenesis; the exact mechanism remains to be elucidated (Dou et al., 2018).

The other part of ubiquitination mediates the NP process by modifying the activity of synaptic proteins and ion channels. Studies on low voltage-gated calcium channels suggest that $\mathrm{Ca}^{2+}$ elevation in sensory neurons is associated with NP (Bourinet et al., 2014; François et al., 2014). Rab3-interactive molecule (RIM) can be associated with N-type voltage-dependent calcium channels. Rab3-interactive molecule-1 $\alpha$ (RIM1 $\alpha$ ) upregulates the expression of CaV2.2 by recruiting and coupling with $\mathrm{CaV} 2.2$. This enables the rapid and synchronized release of neurotransmitters at the presynaptic site to mediate NP. Other studies have demonstrated that Fbxo3 affects the activity of CaV2.2 by inhibiting fbxl2-dependent RIM1 ubiquitination. Moreover, Mas-related G-protein-coupled receptor subtype C (MrgC) ubiquitination affects $\mathrm{RIM} 1 \alpha / \mathrm{Ca}_{V} 2.2$ cascade and then reduces intracellular calcium concentration to participate in the occurrence and maintenance of chronic pain (Marangoudakis et al., 2012; Lai et al., 2016; Sun et al., 2019).

Ubiquitination can also regulate NP through nociceptive information modulation and synaptic function regulation in nociceptive neurons (Kiris et al., 2014). TNF- $\alpha$ impedes presynaptic active zone protein (Munc13-1) ubiquitination in the 
TABLE 1 | Ubiquitination in animal models of chronic pain.

\begin{tabular}{|c|c|c|c|c|}
\hline Animal models & Types of pain & The characteristics & Ubiquitination in models & References \\
\hline $\mathrm{CCl}$ & NP & $\begin{array}{l}\text { Produces unilateral peripheral } \\
\text { mononeuropathy associated with } \\
\text { nerve compression and } \\
\text { neuroinflammatory lesions }\end{array}$ & $\begin{array}{l}\text { Investigate the function of E3 } \\
\text { ubiquitin ligase, deubiquitinase } \\
\text { USP5 }\end{array}$ & $\begin{array}{l}\text { García-Caballero et al., 2014; Lai } \\
\text { et al., } 2018\end{array}$ \\
\hline SNL & NP & $\begin{array}{l}\text { More extensive surgery, injury, and } \\
\text { separation of intact spinal } \\
\text { segments }\end{array}$ & $\begin{array}{l}\text { Study the influence of protein } \\
\text { ubiquitination on the development } \\
\text { of NP }\end{array}$ & $\begin{array}{l}\text { Lin et al., 2015; Lai et al., 2016; Liu } \\
\text { et al., 2019; Tomita et al., } 2019\end{array}$ \\
\hline SNI & NP & $\begin{array}{l}\text { Much easier independent of the } \\
\text { sympathetic system and last for } \\
\text { several weeks, }\end{array}$ & $\begin{array}{l}\text { Used to study drugs associated } \\
\text { with USP }\end{array}$ & $\begin{array}{l}\text { Caterina et al., 1997; } \\
\text { Garcia-Caballero et al., 2019; } \\
\text { Huang et al., } 2020\end{array}$ \\
\hline Formalin and CFA model & Inflammatory Pain & $\begin{array}{l}\text { Simulate inflammatory lesions be } \\
\text { used as a disease model of arthritis }\end{array}$ & $\begin{array}{l}\text { Understand the mechanism of the } \\
\text { ubiquitin system }\end{array}$ & Cottrell et al., 2006 \\
\hline
\end{tabular}

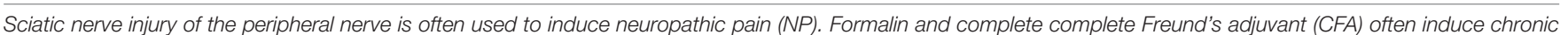

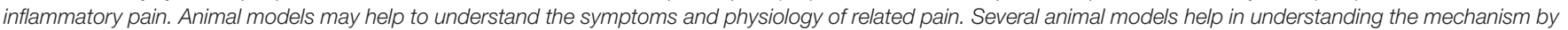
which the ubiquitin system regulates chronic pain.

spinal cord, which promotes the synaptic activity of nociceptive neurotransmission in NP (Lindenlaub et al., 2000; Hsieh et al., 2018). The reduction of ubiquitination of transporter proteins induces the upregulation of glycine transporter 2 (GlyT2) activity, which affects noxious signal conduction (VillarejoLópez et al., 2017). Experiments have shown that periaqueductal gray matter (PGM) in the midbrain, which is involved in pain processing and regulation, could be overexcited and dysfunctional in the face of stress. This process is accompanied by the activation of the ubiquitination system, which may contribute to excruciating pain (Quan et al., 2005). Some drug researches are also based on the role of ubiquitination in pain. For example, metformin can eliminate the abundance of ubiquitinated proteins, which can achieve analgesia by inhibiting cell apoptosis (Weng et al., 2019). In brief, these results emphasize that inhibition of the ubiquitination process of proteins or ion channels may achieve adequate chronic pain relief. Therefore, we summarized the possible mechanisms and potential targets of the abovementioned ubiquitination process of NP regulation, aiming to provide new ideas and experimental evidence for the application of strategies to promote the treatment of chronic pain by influencing the ubiquitination process.

\section{SUMOylation and Neuropathic Pain}

SUMOylation is a small ubiquitin-like modifier (SUMO) protein family coupled to lysine residues (Yang et al., 2017) and is correlated with ubiquitination. It is an important posttranslational protein modification that participates in NP transmission and modulation (Henley et al., 2014). The members of the collapsin response mediator protein (CRMP) family are an effect of neuronal polarity and synapse dynamics. Dysregulation of CRMP has now been described in numerous diseases (Tan et al., 2014). CRMP2 SUMOylation has been reported as the main factor that mediates chronic pain (Moutal et al., 2019). Studies have shown that CRMP2 SUMOylation can regulate voltagegated ion channels, especially the sodium channels in the pain signaling process (Dustrude et al., 2013; Baumann and Kursula, 2017; Bennett et al., 2019), which are upregulated to induce NP (Barbosa and Cummins, 2016). Precisely, the combination of CRMP2 and SUMO controls the expression and density of Nav1.7, thus affecting its activity (Dustrude et al., 2016; FrançoisMoutal et al., 2018a; Moutal et al., 2018). In addition, the E2 SUMO conjugating enzyme (Ubc9) is necessary for SUMOylation and interacts with CPMP2 to reduce CRMP2 SUMOylation, which in turn reduces Nav1.7 current to alleviate NP (FrançoisMoutal et al., 2018b; Moutal et al., 2020). Therefore, preventing CRMP2 SUMOylation may be an effective target to reverse NP (Khanna et al., 2020). Thus, further research is necessary before translating preclinical findings into the clinic setting. There are many clinical challenges to developing SUMOylation enzyme inhibitors, notably to determine which specific targets and predictive indicators are targeted, in order to determine what kind of specific mechanisms may be more beneficial.

\section{Ubiquitin Ligase Modulation of Neuropathic Pain}

Ubiquitin ligase is the most critical factor in determining specificity during protein ubiquitination. E3 ubiquitin ligase affects the development of pain by promoting protein ubiquitination and degradation. Since E3 ligase determines the specificity of the reaction, they have attracted the most attention. E3 ubiquitin ligase includes three families: HECT (homologous to the E6AP carboxyl terminus), RING (really interesting new gene), and U-box domains (Zheng and Shabek, 2017).

It is well known that E3 ubiquitin ligase can regulate ion channel protein levels through ubiquitination. The latepromoting complex/RING body, anaphase-promoting complex $(\mathrm{APC} / \mathrm{C})$, is a cullin-RING-E3 ubiquitin ligase. Its co-activator (Cdh1) is essential for proliferating cells and terminally differentiated neurons. It has been revealed that downregulation of the Cdh1 signal in spinal dorsal horns contributes to the maintenance of mechanical allodynia after nerve injury in rats; thus, it may upregulate the expression of Cdh1 in the spinal cord to induce pain relief (Hu et al., 2016).

Neural precursor cell expressed developmentally downregulated protein 4 (NEDD-4) is a specific E3 ubiquitin ligase regulating $\mathrm{N}$-methyl-D-aspartate (NMDA) receptors (NMDARs) with the GluN2D (NMDAR subtypes) subunit 
through ubiquitination-dependent downregulation (Goel et al., 2015). Specifically, NMDARs are a family of glutamate-gated ion channels that can regulate various central nervous system (CNS) functions. The hypo- or hyper-activation of NMDARs is intimately associated with certain neurological diseases (such as chronic pain, neurodegenerative diseases). Nedd4 can attenuate NP via ubiquitination-dependent downregulation of the NMDAR of the GluN2D subunit (Gautam et al., 2013). Besides, several studies have revealed that the NEDD4 family of E3 ubiquitin ligase can effectively regulate the Nav channels (Eaton et al., 2010). As mentioned earlier, the upregulation of Nav1.7 and Nav1.8 leads to NP. Each Nav subtype has a PY (PPxY) motif at the end of subunit C, making them a target for the NEDD4 ubiquitin ligase family. NEDD-4 like (NEDD4-2) is a ubiquitin-protein ligase that belongs to the NEDD4 family of E3 ubiquitin ligase. Therefore, NEDD4-2 can ubiquitinate Nav1.7 and Nav1.8 and then regulate the ion channel of the cell membrane (Staub et al., 2000). Specifically, NEDD4-2 exists and acts on Nav1.7 and Nav1.8 in dorsal root ganglion (DRG) neurons. When the peripheral nerve is injured, NEDD4-2 in the neuron is downregulated and then disorders Nav, leading to nervous overexcitement and pain (Ekberg et al., 2014; Laedermann et al., 2014). NEDD4-2 regulates nociceptive sensations, and its dysfunction causes NP occurrence. Therefore, active NEDD4-2 can inhibit the upregulation of sodium channels to cure NP (Bongiorno et al., 2011; Cachemaille et al., 2012; Laedermann et al., 2013, 2014; Figure 1).

Cav3.2 channels can be ubiquitinated and are capable of intracellular modification and degradation. The ubiquitination state of Cav3.2 channel in the pain pathway is regulated by the interaction of HECT E3 ligase E3 ubiquitin-protein ligase 1 (WWP1) and USP5, which can regulate the stability of the T-channel protein in the plasma membrane. WWP1 binds to intracellular domains III-IV regions of Cav3.2 T-type and modify specific lysine residues in this region. Preventing the enhancement of this current may potentially combat the development of pain (García-Caballero et al., 2014). The bone morphogenetic protein (BMP) signal downstream of highwire E3 ligase can stimulate nociceptors. The upregulation of the BMP signal leads to a significant increase in $\mathrm{Ca}^{2+}$ current, which is based on physiologically sensitized nociceptors and nociceptive behavior (Honjo and TraceyJr., 2018).

Pellino 1, a critical mediator in various immune receptor signaling pathway molecules, forms the conserved E3 ubiquitin ligase family. It can regulate $\mathrm{NP}$ by regulating $\mathrm{MAPK} /$ nuclear factor kappa B (NF- $\mathrm{B}$ ) signaling in the spinal cord (Börner and Kraus, 2013; Wang et al., 2020). Also, E3 ubiquitin ligase Caritas $\mathrm{B}$ cell lymphoma $(\mathrm{Cbl})$ is a highly conserved ubiquitin ligase expressed in both normal and tumor cells. Besides, c-Cbl can relieve pain by inhibiting the activation of spinal microglia and reducing the release of inflammatory factors. A study found that nerve injury could downregulate the expression of $\mathrm{c}$-Cbl, which leads to the activation of microglia, the increase of inflammatory factor release, and the occurrence of NP through the extracellular signal-regulated kinase (ERK) pathway (Chen et al., 2014; Zhang et al., 2019a). Therefore, increasing c-Cbl could relieve NP (Xue et al., 2018). Interestingly, when the expression of E3 ubiquitin ligase $\mathrm{Cbl}$ family increases, it reduces the analgesic effect of interleukin 2 (IL-2) by increasing ubiquitination of Zeta-chain associated protein 70 (ZAP70) and phospholipase C- $\gamma 1$ (PLC- $\gamma 1$ ) (Jeong et al., 2018). Thus, ubiquitin and E3 ubiquitin ligases $\mathrm{c}-\mathrm{Cbl}$ can regulate the development of NP by reducing the production of IL-2. These findings indicate that the ubiquitin E3 ligase mainly decreases NP by modulating ion channel activity and influencing different signaling pathways. This mechanism of action illustrates how the interdependence between E3 ubiquitin ligase and its substrate protein can provide new therapeutic targets. Therefore, the effects of E3 ubiquitin ligase should be considered when preventing the development of neuralgia after nerve injury.

\section{Role of the Deubiquitinating Enzyme}

Both deubiquitination and ubiquitination are involved in maintaining cell homeostasis. Ubiquitin chain, mediated by DUB, is vital in various cellular processes. USP is a cysteine deubiquitinase and USP5 is recognized to be explicitly polyubiquitin, which is not bound to the target protein and is involved in pain development (Kowalski and Juo, 2012; Ning et al., 2020). Deubiquitination of the channel mediates Cav3.2 T-type calcium by deubiquitinase USP5. When the nerve is damaged, USP5 enhances the deubiquitination of the Cav3.2 channel in the dorsal horn, increasing T-type calcium current, which in turn causes pain hypersensitivity (Gadotti et al., 2015; Gadotti and Zamponi, 2018; Ozaki et al., 2018). Specifically, USP5 is upregulated in NP. Meanwhile, a specific amino acid region in the zinc-finger ubiquitin-specific protease (cUBP) domain of USP5 interacts with the III-IV linker region of the Cav3.2 T-type calcium channel. The reduction of the ubiquitination of the Cav3.2 channel increases the stability of the Cav3.2 channel at the cell surface. Therefore, through disruption, the interaction between USP5 and Cav3.2 channel inhibits the expression of Cav3.2; hence, inhibiting T-type calcium current may alleviate NP (Garcia-Caballero et al., 2016). Some factors also affect the interaction between USP5 and Cav3.2 channels, such as IL-1 recognition (Stemkowski et al., 2017), USP5 SUMOylation disorder (Garcia-Caballero et al., 2019), and TRPV1 nociceptors (Stemkowski et al., 2016). Therefore, these factors also reduce Cav3.2 channel activity by weakening USP5 regulation and increasing channel ubiquitination to achieve the purpose of analgesia (García-Caballero et al., 2014; Joksimovic et al., 2018; Figure 2). For therapeutic purposes, interference with USP5/t-type channel interaction will specifically target a process involving abnormal upregulation of channel activity while maintaining normal channel function, thereby reducing the risk of adverse side effects.

Another deubiquitination enzyme, ubiquitin C-terminal hydrolase L1 (UCHL1), is crucial in neurological diseases. As the UCH-L1 activity increases, ubiquitin expression is upregulated. Extracellular ubiquitin is an agonist of CXC motif chemokine receptor type 4 (CXCR4), which is involved in several pathological conditions, such as immunologic, oncologic, and neurologic disorders. Ubiquitin and CXCR4 may lead to microglial activation and NP. Thus, inhibiting spinal cord UCHL1 and suppressing ubiquitin expression and microglial activation may be effective (Cheng et al., 2016). Although there 


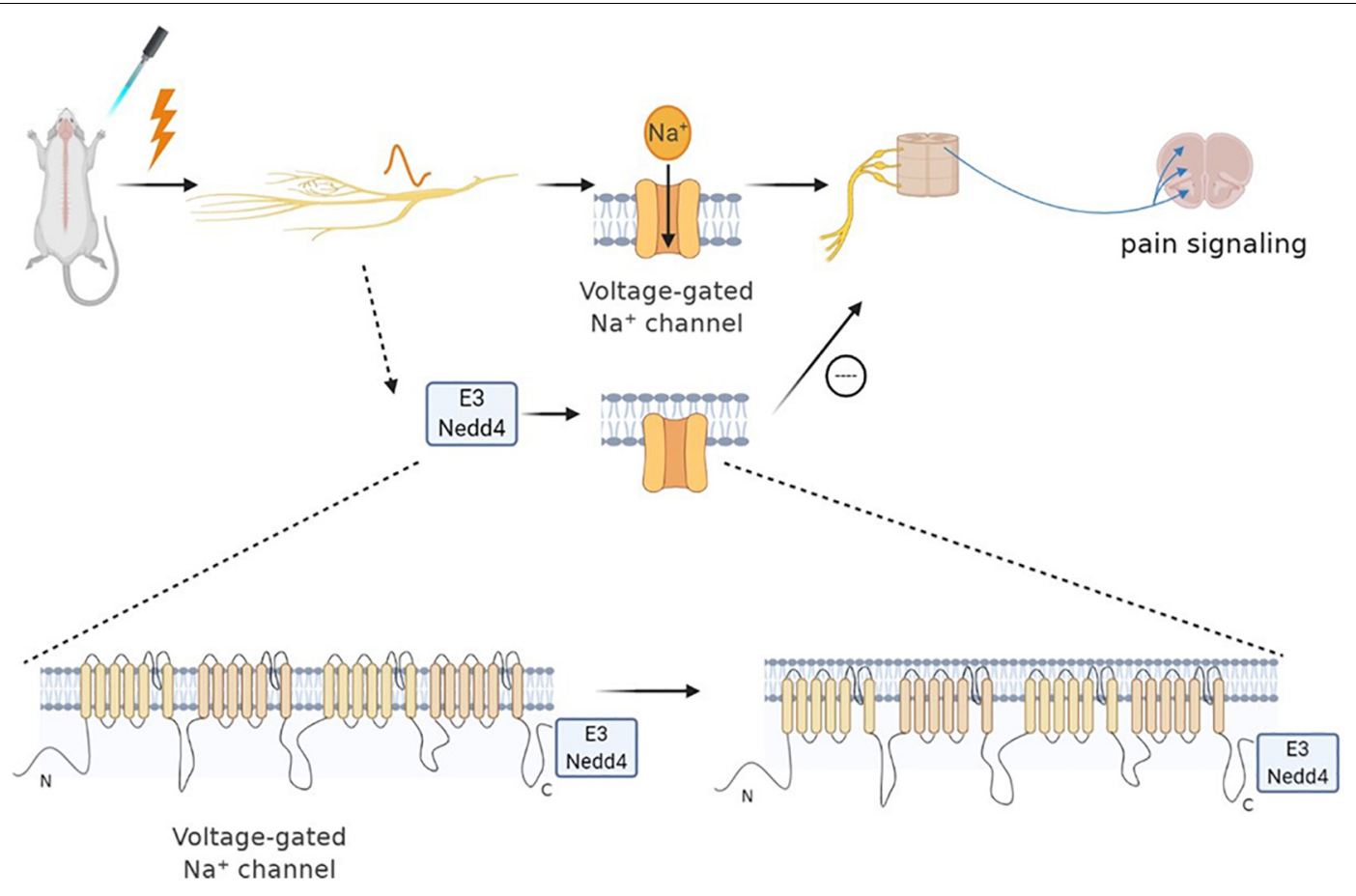

FIGURE 1 | Neural precursor cell expressed developmentally downregulated protein 4 (NEDD4) family of E3 ubiquitin ligase can effectively regulate Nav channels. Sodium channels play an important role in neuropathic pain. When nociceptors are activated, Nav1.7 and Nav1.8 are upregulated, leading to pain. The NEDD4 family of E3 ubiquitin ligase can react on sodium ion channels to ubiquitinate them and promote the channel endocytosis. Specifically, NEDD4 ubiquitin ligase can react with the PY motif at the end of the $\mathrm{C}$ subunit of each Nav subtype, thereby regulating the expression of the Nav channel, as well as the current density and neuronal excitability. Therefore, the pain signal of sensory neurons can be reduced indirectly by regulating the activity of NEDD4-2.

is limited information on DUBs in published early preclinical trials, some information can be emphasized. DUB can regulate the stability and degradation of proteins through a variety of cellular pathways. Here, we present evidence that DUBs can act as a potent regulator of chronic pain processing by increasing the stability of the T-channel or promoting the activation of microglia. This may provide a theoretical basis for the development of more effective chronic pain therapeutics.

\section{Ubiquitin-Proteasome System in Neuropathic Pain}

UPS is a selective non-lysosomal proteolytic system in which substrates are labeled with ubiquitin and can be degraded by proteasomes (Ji and Kwon, 2017; Caputi et al., 2019). The necessary step in the degradation pathway of the proteasome is the formation of ubiquitin-protein conjugates. Covalent binding of ubiquitin ligase and its target molecule leads to molecular degradation. This system can degrade various cellular proteins that can regulate cell growth or function (Figure 3). UPS affects NP by degrading several proteins essential to synaptic plasticity; its downregulation can effectively relieve pain (Hegde, 2010). UPS activity increases during nerve injury, leading to hyperalgesia. Proteasome inhibitors can prevent and reverse NP by concentrating protein systems, including protein systems that control the release of dynorphin $\mathrm{A}$ and calcitonin generelated peptide (CGRP) and the postsynaptic effect of dynorphin
A (Moss et al., 2002; Ossipov et al., 2007). Recent studies suggest that reducing proteasome degradation of Cav3.2 T-type calcium channels is associated with persistent pain. When proteasome degradation is inhibited, which subsequently inhibits the upregulation of USP5, the protein level of Cav3.2 in nociceptors is increased (Tomita et al., 2019). In addition, when the UPS was activated, the degradation of glutamate transporters is enhanced, resulting in mechanical hyperalgesia (Manning, 2004; Zavrski et al., 2005; Yang et al., 2008; StocktonJr., Gomes et al., 2015). Accordingly, inhibition of ubiquitin proteasomemediated degradation of glutamate transporters may offer treatment options for certain neurological diseases and chronic pain. While this methodology deserves further investigation, considering the diversified effects of the proteasome, the use of broad-spectrum proteasome inhibitors may be flawed, and the development of selective inhibitors for chronic pain may be a more effective method. In this sense, developing methods for reducing chronic pain with selective inhibitors could be a more effective approach.

\section{ROLE OF THE UBIQUITIN SYSTEM IN INFLAMMATORY PAIN}

The etiology and pathogenesis of NP and inflammatory pain remain inconsistent, and their targets in the ubiquitin system are also different. Therefore, novel therapeutic targets for chronic 


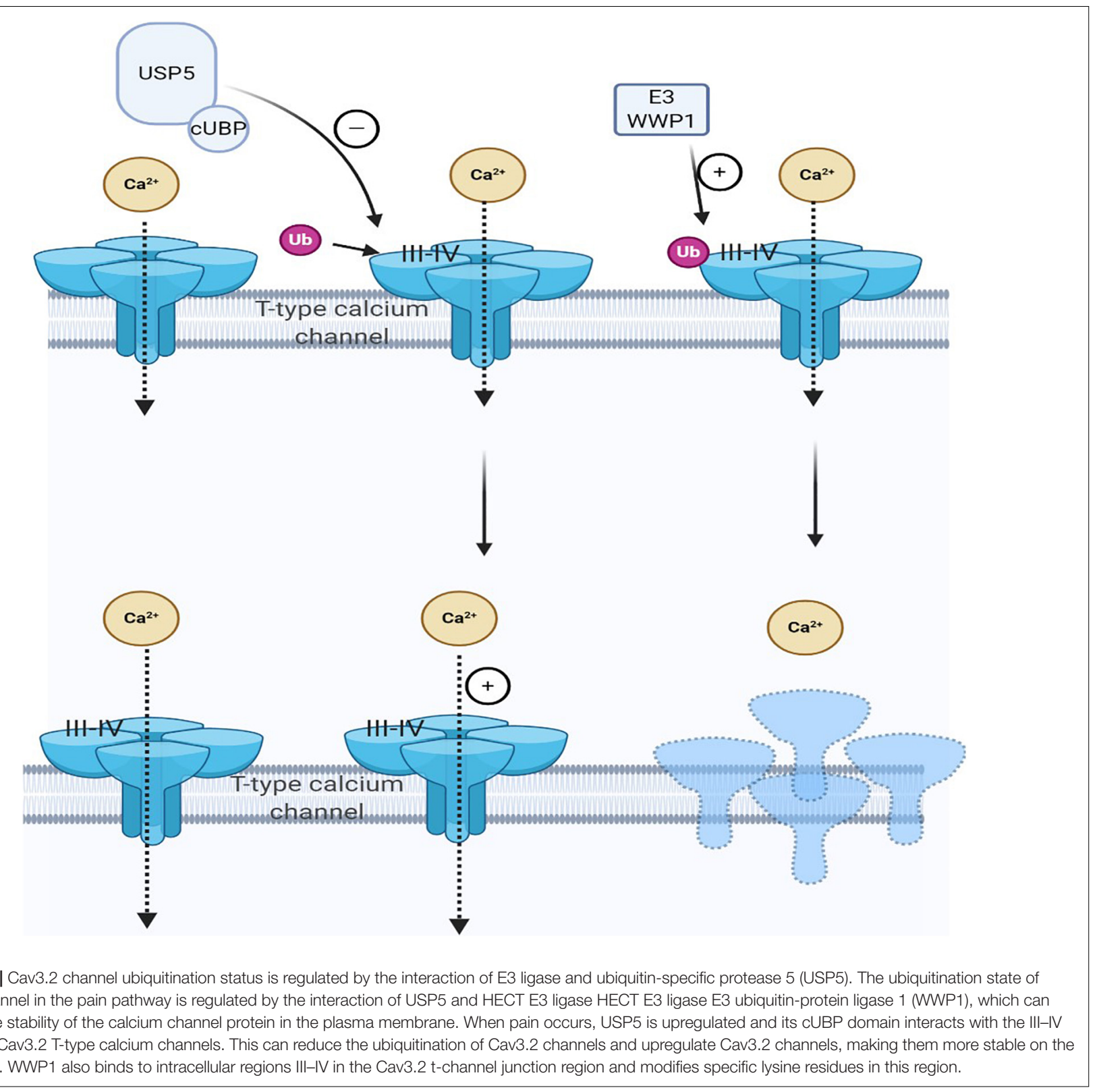

pain states accompanying inflammatory processes are urgently needed. As described below, inflammatory disease models show the relief of inflammatory pain by inhibiting the ubiquitination process of several proteins. Therefore, it is necessary to explore the role of the ubiquitin system that regulates pain signals during chronic inflammation in order to reflect the mediated analgesia in different forms of chronic pain.

\section{Ubiquitination in Inflammatory Pain}

Ubiquitination is significant in inflammatory pain. Acute inflammation is a key player in peripheral sensitization and local tissue inflammation-evoked pain. The pain persists and becomes chronic during inflammation resolution. Short-term stimulation of SP induces TRPV1 polyubiquitination, which has an impact on chronic visceral pain. Various pro-inflammatory mediators, such as histamine and bradykinin, express function by regulating TRPV1. The degree of abdominal pain in patients is related to the increased expression of TRPV1. The feedback regulation of TRPV1 by SP also participates in the inflammatory visceral pain. Therefore, drugs that block SP-mediated TRPV1 ubiquitination may reduce chronic pain after inflammation (Lapointe et al., 2015).

The inhibition of glycine is weakened after peripheral tissue damage, which is considered a critical factor in the occurrence of inflammatory pain. The inhibition of glycine can increase the excitability and spontaneous activity of spinal cord nociceptive neurons during inflammatory pain. Studies found that the activity of the glycine receptor subunit (GlyRs- $\alpha 1$ ) is dependent on ubiquitination, which may help glycinergic inhibition after peripheral inflammation. Therefore, ubiquitin 


\section{Ubiquitination system}

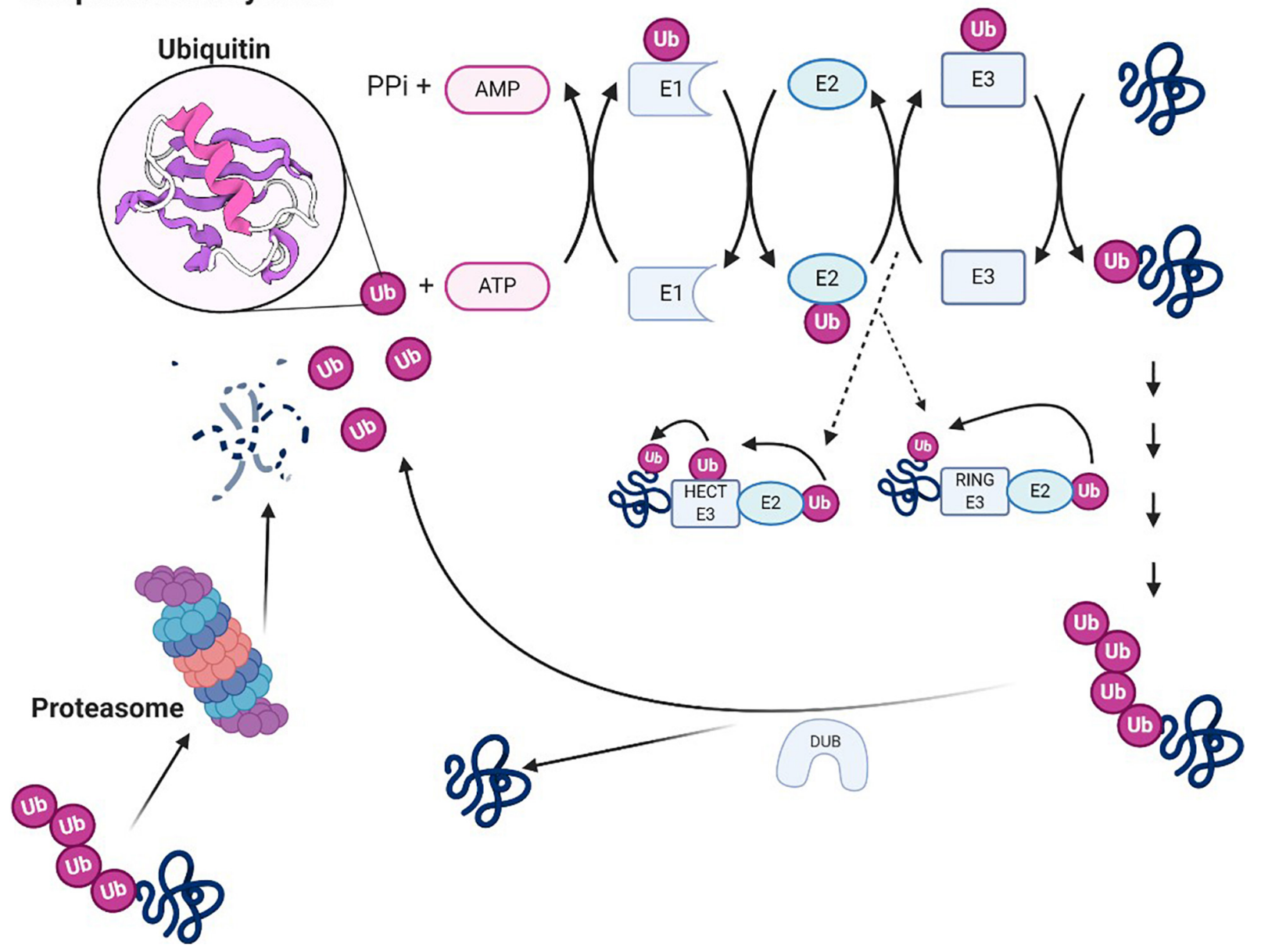

FIGURE 3 | Ubiquitin system. Ubiquitin molecules can be covalently linked to other substrates to form ubiquitin chains. A chain of four or more ubiquitin units constitutes proteasome 26S. Ubiquitin is an ATP-dependent process catalyzed by three enzymes (E1, E2, and E3), which also confer specificity to the process. The first reaction catalyzed by E1 is responsible for the activation of ubiquitin. E1 transfers ubiquitin on cysteine to E2. Through the activity of transferase, E2 transfers the ubiquitin to E3 ligase (two groups of protein ubiquitin ligase, HECT E3 enzymes and ring E3s, the way they transfer ubiquitin is exactly different), which binds ubiquitin to the Lys residue of the target protein. Polyubiquitinated protein can be degraded by $26 \mathrm{~S}$ proteasome, and ubiquitin can be recovered under the action of the deubiquitinating enzyme.

modification of Glyrs- $\alpha 1$ reduces the spinal glycinergic inhibition in peripheral inflammation. Furthermore, preventing Glyrs$\alpha 1$ from ubiquitination, restoring Glyrs- $\alpha 1$-mediated synaptic transmission can generate analgesic action (Zhang et al., 2019b). Despite these studies further clarifying the role of ubiquitination in inflammatory pain, more preclinical trials are still necessary. The development of new drugs targeting specific mechanisms may facilitate translation of these findings from bench to bedside.

\section{Role of the Deubiquitinating Enzyme in Inflammatory Pain}

As mentioned earlier, USP5 also mediates inflammatory pain by enhancing the Cav3.2 channel activity. Inflammatory mediators, bradykinin, also increase the number of sensory neurons expressing T-type $\mathrm{Ca}^{2+}$ channels (Huang et al., 2016; Sekiguchi et al., 2018). USP5 binds to III-IV linkers in Cav3.2
(Garcia-Caballero et al., 2016). Cav3.2 channel ubiquitination is the substrate of USP5, and its association with USP5 leads to changes in Cav3.2 protein level and current density. USP5mediated regulation of Cav3.2 is abnormally enhanced in chronic pain. These data suggest that USP5 is a regulator of chronic pain associated with inflammatory processes (García-Caballero et al., 2014).

Ubiquitin-specific proteases or deubiquitin enzymes remove ubiquitin groups from the degraded target proteins, thereby improving protein stability. Therefore, USP5 knockout by shRNA can increase Cav3.2 ubiquitination, decrease Cav3.2 protein level, and decrease calcium current. It was found that inhibition of USP5 in vivo or decoupling of USP5 from the intrinsic Cav3.2 channel through intrathecal delivery of Tat peptide can protect from inflammatory pain. Therefore, targeting Cav3.2 deubiquitination by USP5 is a potential target for pain conditions associated with inflammatory disorders (Gadotti et al., 
2015). According to data from basic research, combined with experimental pain models, the method of inhibiting DUBs has been studied in preclinical studies. It can be concluded that the mechanisms listed above contribute to relieve chronic pain, especially inflammatory pain.

\section{Ubiquitin Ligase Modulation of Inflammatory Pain}

E3 ubiquitin ligase is a key component that generates specific reactions through substrate recognition (Qiu et al., 2011). The substrates of NEDD4-2 mainly include the epithelial sodium channel $(\mathrm{ENaC})$ and neurotrophin receptor (TrkA). NEDD42 heterozygous mice can provide a new model for studying inflammatory pain, which causes the mice to be more hyperactive and increase their sensitivity to pain during central sensitization and inflammation. This is likely to be caused by decreased levels of NEDD4-2, leading to increased reactivity of the substrate TrkA to nerve growth factor (NGF). Therefore, a full complement of E3 ubiquitin ligase is necessary for inflammatory pain relief (Yanpallewar et al., 2016).

Ubiquitin protein ligase E3 component n-recognin 5 (UBR5) is a kind of HECT (homologous to E6AP C-terminus), which can recognize another E3 ubiquitin ligase of N-Degrons. It has the catalytic ability to directly identify and link ubiquitin to protein degradation. UBR5 can regulate neuronal plasticity by activating NMDARs in the CNS. It participates in the pathological process of CNS diseases through modified ubiquitination, which is crucial in regulating nociception (Pierre et al., 2008). This adjustment is mainly through the subsequent process. Additionally, for CFAinduced chronic inflammatory pain, the increased expression of circRNA-Filip11 (serine A interacting protein 1-like) in the spinal cord regulates nociception by UBR5. The downregulation of UBR5 significantly reduced the nociceptive response induced by Lenti-Filip11. miRNA-1224-mediated splicing of circRNAFilip11 regulates chronic inflammatory pain throughout by targeting UBR5. Therefore, the development of inflammatory pain could be reduced by inhibiting UBR5 (Pan et al., 2019).

Myc binding protein 2 (MYCBP2) is another E3 ubiquitin ligase, which can inhibit neuron growth and synapse formation by regulating various signaling pathways. Research has proven that its selective deletion in macrophages can reduce zymogeninduced inflammatory pain and promote the resolution of inflammation (Pierre et al., 2018). Other E3 ubiquitin ligases, such as ligand of numb proteins X1/2 (LNX1/LNX2), are functional regulators of neuronal GlyT2. LNX1 and LNX2 interact with GlyT2 and ubiquitinate the C-terminal cluster of the transporter lysine to control the expression and activity of GlyT2. Changes in the expression or activity of GlyT2 lead to the emptying of synaptic vesicles, which may be related to inflammatory pain pathology (de la Rocha-Munoz et al., 2019). Furthermore, the phosphorylation of E3 ubiquitin ligase Cbl-b weakens its binding and ubiquitination to GLUN2B (a type of NMDAR subunit), thereby inhibiting GLUN2B-mediated synaptic currents and inflammatory pain (Zhang et al., 2020).

HUWE1 (HECT, UBA, and WWE domain contains 1), an E3 ubiquitin ligase located in the spinal cord synapse, specifically interacts with GlyRs- $\alpha 1$. It can reduce the surface expression of GlyRs- $\alpha 1$ by ubiquitinating GlyRs- $\alpha 1$. Ubiquitin modification of GlyRs- $\alpha 1$ is a crucial way to reduce peripheral inflammation inhibited by spinal cord glycine. After the surrounding tissues are injured, the inhibitory effect of glycine is weakened, which leads to the occurrence of inflammatory pain. Previous studies showed that HUWE1 contributed to glycinergic disinhibition.

TABLE 2 | Available potential targets of E3 ubiquitin ligases and DUBs for chronic pain.

\begin{tabular}{|c|c|c|c|c|c|}
\hline Categories & $\begin{array}{l}\text { The names of the } \\
\text { enzymes }\end{array}$ & Targets & Pain relief & Types of chronic pain & References \\
\hline \multirow[t]{11}{*}{ E3 ubiquitin ligases } & WWP1 & Cav3.2 & $\uparrow$ & NP & García-Caballero et al., 2014 \\
\hline & Fbxo3 & TRAF2/TNIK/GluR1 Cascade & $\downarrow$ & NP & Lai et al., 2016 \\
\hline & $\mathrm{Fbx045}$ & Munc13-1 & $\downarrow$ & NP & Lindenlaub et al., 2000 \\
\hline & $\mathrm{APC} / \mathrm{C}$ & Cdh1 & $\uparrow$ & NP & Goel et al., 2015 \\
\hline & NEDD4-2 & GluN2D & $\uparrow$ & NP & Staub et al., 2000; Eaton et al., 2010 \\
\hline & & Nav1.7, Nav1.8 & $\uparrow$ & & \\
\hline & Peli1 & MAPK/NF-кB signal & $\downarrow$ & NP & (Börner and Kraus, 2013 \\
\hline & $\mathrm{c}-\mathrm{Cbl}$ & microglia & $\uparrow$ & NP & Kowalski and Juo, 2012 \\
\hline & & ZAP70, PLC- $\gamma 1$ & $\downarrow$ & & \\
\hline & HUWE1 & GlyRs- $\alpha 1$ & $\downarrow$ & Inflammatory pain & Sekiguchi et al., 2018 \\
\hline & UBR5 & circRNA-Filip11 & $\downarrow$ & Inflammatory pain & Pierre et al., 2018 \\
\hline \multirow[t]{2}{*}{ DUBs } & USP5 & Cav3.2 & $\downarrow$ & NP, Inflammatory pain & García-Caballero et al., 2014 \\
\hline & UCHL1 & Microglial & $\downarrow$ & $\mathrm{NP}$ & Ji and Kwon, 2017 \\
\hline
\end{tabular}

$\uparrow$ Represents upregulation of the enzymes can relieve pain.

$\downarrow$ Represents downregulation of the enzymes can relieve pain.

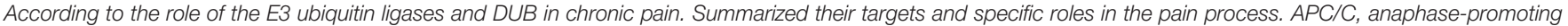

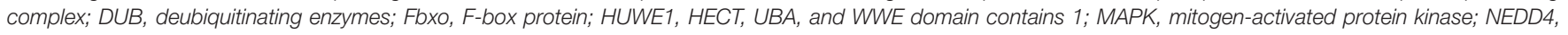

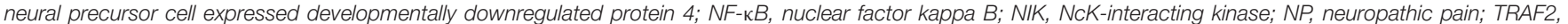

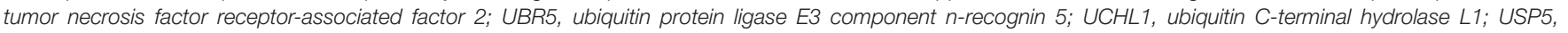
ubiquitin-specific protease 5; WWP1, HECT E3 ligase E3 ubiquitin-protein ligase 1. 
Additionally, knockout of HUWE1 can attenuate GlyRs- $\alpha 1$ ubiquitination, improve glycinergic synaptic transmission, and reduce inflammatory pain. Therefore, it can interfere with the activity of HUWEland produce analgesic effects by restoring GlyRs- $\alpha 1$-mediated synaptic transmission (Zhang et al., 2019b). This E3-ubiquitin ligase-mediated protein ubiquitination regulates chronic inflammatory pain via controlling the level of substrate proteins and then possibly adjusts synaptic efficacy. The results will offer a basis for future research on the role of protein ubiquitination in inflammatory pain (Table 2 ).

\section{Ubiquitin-Proteasome System in Inflammatory Pain}

UPS is a key intracellular regulator of inflammation and pathological pain. Intracellular pathways mediated by UPS affect inflammatory pain. It can affect the expression of sensory neuropeptides, which can regulate pain and inflammation.

UPS inhibitors can prevent inflammatory pain. Proteasome inhibitor MG132 reduces inflammatory pain by targeting the sensory neuropeptide SP of the CNS in arthritis. Specifically, the $\mathrm{NF}-\kappa \mathrm{B}$ family is a major modulator of immune and inflammatory processes following injury and infection (Napetschnig and $\mathrm{Wu}$, 2013). MG132 can inhibit the activation of NF- $\kappa$ B to reverse the inflammatory pain (Ahmed et al., 2017). The generation of new proteasome inhibitors may represent a new pharmacotherapy for inflammatory pain.

Whether the application of a wide range of proteasome inhibitors may have complex effects in these ubiquitination pathways, even limited to the nervous system, and whether it causes adverse effects require careful consideration.

\section{PERSPECTIVES AND CONCLUSION}

A large body of evidence has provided a partial explanation of how changes in the ubiquitin system result in improved chronic pain response.

The examples presented here provide only a glimpse into the expanding role of ubiquitination in regulating chronic pain. The ubiquitin system is essential not only in the process of regulating chronic pain but also in pain treatment. However, understanding the molecular mechanisms underlying

\section{REFERENCES}

Ahmed, A. S., Ahmed, M., Li, J., Gu, H. F., Bakalkin, G., Stark, A., et al. (2017). Proteasome inhibitor MG132 modulates inflammatory pain by central mechanisms in adjuvant arthritis. Int. J. Rheumatic Dis. 20, 25-32. doi: 10.1111/ 1756-185x.12353

Barbosa, C., and Cummins, T. R. (2016). Unusual voltage-gated sodium currents as targets for pain. Curr. Topics Membranes 78, 599-638. doi: 10.1016/bs.ctm. 2015.12.005

Baumann, A., and Kursula, P. (2017). SUMO on CRMPs - wrestling for pain? Channels (Austin, Tex) 11, 265-267. doi: 10.1080/19336950.2017.1311758

Bennett, D. L., Clark, A. J., Huang, J., Waxman, S. G., and Dib-Hajj, S. D. (2019). The role of voltage-gated sodium channels in pain signaling. Physiol. Rev. 99, 1079-1151. doi: 10.1152/physrev.00052.2017 pain regulation by ubiquitin remains challenging because more components of the ubiquitin system are linked to chronic pain, such as ubiquitin ligase, UPS, and DUBs. And the differences between NP and inflammatory pain are not reported to be specific in ubiquitination. The underlying specific difference needs to be revealed in future studies.

In the process of pain, the ubiquitin signaling pathway often acts in cascade with other nociceptors, which further complicates chronic pain. Dysregulation of gene expression mediated by epigenetic mechanisms is crucial in the occurrence and maintenance of chronic pain caused by multiple reasons. To understand the dynamics and complexity of such events, it is necessary to conduct comprehensive proteomic and genomic research using various types of chronic pain models.

Understanding how the ubiquitin system affects the development of chronic pain can provide new ideas and strategies for pain treatment. Interfering with the ubiquitin pathway using inhibitors, such as proteasome inhibitors, is an effective strategy to treat chronic pain. The application of these strategies in clinical trials will expand and diversify the scope of chronic pain treatment for more effective therapies of patients in the future. Therefore, a deeper insight into the ubiquitin system will be precious for the future development of chronic pain therapies.

\section{AUTHOR CONTRIBUTIONS}

JC, YD, and JZ contributed to conception and design of the study. JC wrote the first draft of the manuscript. YD accessed data. JZ contributed to manuscript revision. All authors contributed to the article and approved the submitted version.

\section{FUNDING}

This work was supported by grants from the National Natural Science Foundation of China (81870879), Guangzhou Key Laboratory of Mechanism of Spinal Neuropathic Pain, and the Natural Science Foundation of Guangdong Province (2017A030313534), and Guangzhou Key Laboratory of Neuropathic Pain Mechanism at Spinal Cord Level (202102100005).

Bongiorno, D., Schuetz, F., Poronnik, P., and Adams, D. J. (2011). Regulation of voltage-gated ion channels in excitable cells by the ubiquitin ligases Nedd 4 and Nedd4-2. Channels (Austin, Tex) 5, 79-88. doi: 10.4161/chan.5.1.13967

Börner, C., and Kraus, J. (2013). Inhibition of NF- $\kappa$ B by opioids in T cells. J. Immunol. (Baltimore, Md : 1950) 191, 4640-4647. doi: 10.4049/jimmunol. 1300320

Bourinet, E., Altier, C., Hildebrand, M. E., Trang, T., Salter, M. W., and Zamponi, G. W. (2014). Calcium-permeable ion channels in pain signaling. Physiol. Rev. 94, 81-140. doi: 10.1152/physrev.00023.2013

Cachemaille, M., Laedermann, C. J., Pertin, M., Abriel, H., Gosselin, R. D., and Decosterd, I. (2012). Neuronal expression of the ubiquitin ligase Nedd42 in rat dorsal root ganglia: modulation in the spared nerve injury model of neuropathic pain. Neuroscience 227, 370-380. doi: 10.1016/j.neuroscience. 2012.09.044 
Caputi, F. F., Rullo, L., Stamatakos, S., Candeletti, S., and Romualdi, P. (2019). Interplay between the endogenous opioid system and proteasome complex: beyond signaling. Int. J. Mol. Sci. 20:1441. doi: 10.3390/ijms20061441

Caterina, M. J., Schumacher, M. A., Tominaga, M., Rosen, T. A., Levine, J. D., and Julius, D. (1997). The capsaicin receptor: a heat-activated ion channel in the pain pathway. Nature 389, 816-824. doi: 10.1038/39807

Chen, P. C., Bhattacharyya, B. J., Hanna, J., Minkel, H., Wilson, J. A., Finley, D., et al. (2011). Ubiquitin homeostasis is critical for synaptic development and function. J. Neurosci. : Off. J. Soc. Neurosci. 31, 17505-17513. doi: 10.1523/ jneurosci.2922-11.2011

Chen, Y., Kanju, P., Fang, Q., Lee, S. H., Parekh, P. K., Lee, W., et al. (2014). TRPV4 is necessary for trigeminal irritant pain and functions as a cellular formalin receptor. Pain 155, 2662-2672. doi: 10.1016/j.pain.2014.09.033

Cheng, W., Chen, Y. L., Wu, L., Miao, B., Yin, Q., Wang, J. F., et al. (2016). Inhibition of spinal UCHL1 attenuates pain facilitation in a cancer-induced bone pain model by inhibiting ubiquitin and glial activation. Am. J. Transl. Res. 8, 3041-3048.

Cottrell, G. S., Padilla, B., Pikios, S., Roosterman, D., Steinhoff, M., Gehringer, D., et al. (2006). Ubiquitin-dependent down-regulation of the neurokinin-1 receptor. J. Biol. Chem. 281, 27773-27783. doi: 10.1074/jbc.m603369200

de la Rocha-Munoz, A., Nunez, E., Arribas-Gonzalez, E., Lopez-Corcuera, B., Aragon, C., and de Juan-Sanz, J. (2019). E3 ubiquitin ligases LNX1 and LNX2 are major regulators of the presynaptic glycine transporter GlyT2. Sci. Rep. 9:14944.

Dou, Y., Tian, X., Zhang, J., Wang, Z., and Chen, G. (2018). Roles of TRAF6 in central nervous system. Curr. Neuropharmacol. 16, 1306-1313. doi: 10.2174/ 1570159x16666180412094655

Dustrude, E. T., Moutal, A., Yang, X., Wang, Y., Khanna, M., and Khanna, R. (2016). Hierarchical CRMP2 posttranslational modifications control NaV1.7 function. Proc. Natl. Acad. Sci. U.S.A. 113, E8443-E8452.

Dustrude, E. T., Wilson, S. M., Ju, W., Xiao, Y., and Khanna, R. (2013). CRMP2 protein SUMOylation modulates NaV1.7 channel trafficking. J. Biol. Chem. 288, 24316-24331. doi: 10.1074/jbc.m113.474924

Eaton, D. C., Malik, B., Bao, H. F., Yu, L., and Jain, L. (2010). Regulation of epithelial sodium channel trafficking by ubiquitination. Proc. Am. Thoracic Soc. 7, 54-64. doi: 10.1513/pats.200909-096js

Ekberg, J. A., Boase, N. A., Rychkov, G., Manning, J., Poronnik, P., and Kumar, S. (2014). Nedd4-2 (NEDD4L) controls intracellular $\mathrm{Na}(+)$-mediated activity of voltage-gated sodium channels in primary cortical neurons. Biochem. J. 457, 27-31. doi: 10.1042/bj20131275

François, A., Laffray, S., Pizzoccaro, A., Eschalier, A., and Bourinet, E. (2014). Ttype calcium channels in chronic pain: mouse models and specific blockers. Pflugers Archiv. : Eur. J. Physiol. 466, 707-717. doi: 10.1007/s00424-014-1484-4

François-Moutal, L., Dustrude, E. T., Wang, Y., Brustovetsky, T., Dorame, A., Ju, W., et al. (2018a). Inhibition of the Ubc9 E2 SUMO-conjugating enzymeCRMP2 interaction decreases NaV1.7 currents and reverses experimental neuropathic pain. Pain 159, 2115-2127. doi: 10.1097/j.pain.0000000000001294

François-Moutal, L., Scott, D. D., Perez-Miller, S., Gokhale, V., Khanna, M., and Khanna, R. (2018b). Chemical shift perturbation mapping of the Ubc9-CRMP2 interface identifies a pocket in CRMP2 amenable for allosteric modulation of Nav1.7 channels. Channels (Austin, Tex) 12, 219-227. doi: 10.1080/19336950. 2018.1491244

Gadotti, V. M., Caballero, A. G., Berger, N. D., Gladding, C. M., Chen, L., Pfeifer, T. A., et al. (2015). Small organic molecule disruptors of Cav3.2 - USP5 interactions reverse inflammatory and neuropathic pain. Mol. Pain 11:12.

Gadotti, V. M., and Zamponi, G. W. (2018). Disrupting USP5/Cav3.2 interactions protects female mice from mechanical hypersensitivity during peripheral inflammation. Mol. Brain 11:60.

Garcia-Caballero, A., Gadotti, V. M., Chen, L., and Zamponi, G. W. (2016). A cell-permeant peptide corresponding to the cUBP domain of USP5 reverses inflammatory and neuropathic pain. Mol. Pain 12:1744806916642444. doi: 10. $1177 / 1744806916642444$

García-Caballero, A., Gadotti, V. M., Stemkowski, P., Weiss, N., Souza, I. A., Hodgkinson, V., et al. (2014). The deubiquitinating enzyme USP5 modulates neuropathic and inflammatory pain by enhancing Cav3.2 channel activity. Neuron 83, 1144-1158. doi: 10.1016/j.neuron.2014.07.036
Garcia-Caballero, A., Zhang, F. X., Chen, L., M'Dahoma, S., Huang, J., and Zamponi, G. W. (2019). SUMOylation regulates USP5-Cav3.2 calcium channel interactions. Mol. Brain 12:73.

Gautam, V., Trinidad, J. C., Rimerman, R. A., Costa, B. M., Burlingame, A. L., and Monaghan, D. T. (2013). Nedd4 is a specific E3 ubiquitin ligase for the NMDA receptor subunit GluN2D. Neuropharmacology 74, 96-107. doi: 10. 1016/j.neuropharm.2013.04.035

Glickman, M. H., and Ciechanover, A. (2002). The ubiquitin-proteasome proteolytic pathway: destruction for the sake of construction. Physiol. Rev. 82, 373-428. doi: 10.1152/physrev.00027.2001

Goel, P., Manning, J. A., and Kumar, S. (2015). NEDD4-2 (NEDD4L): the ubiquitin ligase for multiple membrane proteins. Gene 557, 1-10. doi: 10.1016/j.gene. 2014.11.051

Hegde, A. N. (2010). The ubiquitin-proteasome pathway and synaptic plasticity. Learn. Memory (Cold Spring Harbor, NY). 17, 314-327. doi: 10.1101/lm. 1504010

Henley, J. M., Craig, T. J., and Wilkinson, K. A. (2014). Neuronal SUMOylation: mechanisms, physiology, and roles in neuronal dysfunction. Physiol. Rev. 94, 1249-1285. doi: 10.1152/physrev.00008.2014

Honjo, K., and Tracey, W. D. Jr. (2018). BMP signaling downstream of the Highwire E3 ligase sensitizes nociceptors. PLoS Genet. 14:e1007464. doi: 10. 1371/journal.pgen.1007464

Hsieh, M. C., Ho, Y. C., Lai, C. Y., Chou, D., Chen, G. D., Lin, T. B., et al. (2018). Spinal TNF- $\alpha$ impedes Fbxo45-dependent Munc13-1 ubiquitination to mediate neuropathic allodynia in rats. Cell Death Dis. 9:811.

Hu, R., Li, L., Li, D., Tan, W., Wan, L., Zhu, C., et al. (2016). Downregulation of Cdh1 signalling in spinal dorsal horn contributes to the maintenance of mechanical allodynia after nerve injury in rats. Mol. Pain 12:1744806916647376. doi: 10.1177/1744806916647376

Huang, D., Liang, C., Zhang, F., Men, H., Du, X., Gamper, N., et al. (2016). Inflammatory mediator bradykinin increases population of sensory neurons expressing functional T-type $\mathrm{Ca}(2+)$ channels. Biochem. Biophys. Res. Commun. 473, 396-402. doi: 10.1016/j.bbrc.2016.02.118

Huang, J., Liu, J., and Qiu, L. (2020). Transient receptor potential vanilloid 1 promotes EGFR ubiquitination and modulates EGFR/MAPK signalling in pancreatic cancer cells. Cell Biochem. Funct. 38, 401-408. doi: 10.1002/cbf. 3483

Jensen, T. S., Baron, R., Haanpää, M., Kalso, E., Loeser, J. D., Rice, A. S., et al. (2011). A new definition of neuropathic pain. Pain 152, 2204-2205.

Jeong, J. S., Kim, H. Y., Shin, B. S., Lee, A. R., Yoon, J. H., Hahm, T. S., et al. (2018). Increased expression of the Cbl family of E3 ubiquitin ligases decreases Interleukin-2 production in a rat model of peripheral neuropathy. BMC Anesthesiol. 18:87. doi: 10.1186/s12871-018-0555-z

Ji, C. H., and Kwon, Y. T. (2017). Crosstalk and interplay between the ubiquitinproteasome system and autophagy. Mol. Cells 40, 441-449.

Joksimovic, S. L., Joksimovic, S. M., Tesic, V., García-Caballero, A., Feseha, S., Zamponi, G. W., et al. (2018). Selective inhibition of $\mathrm{Ca}(\mathrm{V}) 3.2$ channels reverses hyperexcitability of peripheral nociceptors and alleviates postsurgical pain. Sci. Signal. 11:eaao4425. doi: 10.1126/scisignal.aao4425

Khanna, R., Moutal, A., Perez-Miller, S., Chefdeville, A., Boinon, L., and Patek, M. (2020). Druggability of CRMP2 for neurodegenerative diseases. ACS Chem. Neurosci. 11, 2492-2505. doi: 10.1021/acschemneuro.0c00307

Kiris, E., Wang, T., Yanpallewar, S., Dorsey, S. G., Becker, J., Bavari, S., et al. (2014). TrkA in vivo function is negatively regulated by ubiquitination. J. Neurosci. : Off. J. Soc. Neurosci. 34, 4090-4098. doi: 10.1523/jneurosci.4294-13.2014

Kowalski, J. R., and Juo, P. (2012). The role of deubiquitinating enzymes in synaptic function and nervous system diseases. Neural Plasticity 2012:892749.

Kumar, A., Kaur, H., and Singh, A. (2018). Neuropathic Pain models caused by damage to central or peripheral nervous system. Pharmacol. Rep. : PR. 70, 206-216. doi: 10.1016/j.pharep.2017.09.009

Laedermann, C. J., Cachemaille, M., Kirschmann, G., Pertin, M., Gosselin, R. D., Chang, I., et al. (2013). Dysregulation of voltage-gated sodium channels by ubiquitin ligase NEDD4-2 in neuropathic pain. J. Clin. Investigation 123, 3002-3013. doi: 10.1172/jci68996

Laedermann, C. J., Decosterd, I., and Abriel, H. (2014). Ubiquitylation of voltagegated sodium channels. Handbook Exp. Pharmacol. 221, 231-250. doi: 10.1007/ 978-3-642-41588-3_11 
Lai, C. Y., Ho, Y. C., Hsieh, M. C., Wang, H. H., Cheng, J. K., Chau, Y. P., et al. (2016). Spinal Fbxo3-Dependent Fbxl2 ubiquitination of active zone protein RIM1 $\alpha$ mediates neuropathic allodynia through CaV2.2 activation. J. Neurosci. : Off. J. Soc. Neurosci. 36, 9722-9738. doi: 10.1523/jneurosci.1732-16.2016

Lai, C. Y., Hsieh, M. C., Ho, Y. C., Wang, H. H., Chou, D., Wen, Y. C., et al. (2018). Spinal RNF20-mediated histone H2B monoubiquitylation regulates mGluR5 transcription for neuropathic allodynia. J. Neurosci. : Off. J. Soc. Neurosci. 38, 9160-9174. doi: 10.1523/jneurosci.1069-18.2018

Lapointe, T. K., Basso, L., Iftinca, M. C., Flynn, R., Chapman, K., Dietrich, G., et al. (2015). TRPV1 sensitization mediates postinflammatory visceral pain following acute colitis. Am. J. Physiol. Gastrointestinal Liver Physiol. 309, G87-G99.

Lin, T. B., Hsieh, M. C., Lai, C. Y., Cheng, J. K., Chau, Y. P., Ruan, T., et al. (2015). Fbxo3-dependent Fbxl2 ubiquitination mediates neuropathic allodynia through the TRAF2/TNIK/GluR1 cascade. J. Neurosci. : Off. J. Soc. Neurosci. 35, 16545-16560. doi: 10.1523/jneurosci.2301-15.2015

Lindenlaub, T., Teuteberg, P., Hartung, T., and Sommer, C. (2000). Effects of neutralizing antibodies to TNF-alpha on pain-related behavior and nerve regeneration in mice with chronic constriction injury. Brain Res. 866, 15-22. doi: 10.1016/s0006-8993(00)02190-9

Linley, J. E., Rose, K., Ooi, L., and Gamper, N. (2010). Understanding inflammatory pain: ion channels contributing to acute and chronic nociception. Pflugers Archiv. : Eur. J. Physiol. 459, 657-669. doi: 10.1007/s00424-010-0784-6

Liu, S., Karaganis, S., Mo, R. F., Li, X. X., Wen, R. X., and Song, X. J. I. F. N. (2019). $\beta$ Treatment inhibits nerve injury-induced mechanical allodynia and MAPK signaling by activating ISG15 in mouse spinal cord. J. Pain : Off. J. Am. Pain Soc. 21, 836-847. doi: 10.1016/j.jpain.2019.11.010

Manning, D. C. (2004). New and emerging pharmacological targets for neuropathic pain. Curr. Pain Headache Rep. 8, 192-198. doi: 10.1007/s11916-004-0051-7

Marangoudakis, S., Andrade, A., Helton, T. D., Denome, S., Castiglioni, A. J., and Lipscombe, D. (2012). Differential ubiquitination and proteasome regulation of $\mathrm{Ca}(\mathrm{V}) 2.2$ N-type channel splice isoforms. J. Neurosci. : Off. J. Soc. Neurosci. 32, 10365-10369. doi: 10.1523/jneurosci.0851-11.2012

Moss, A., Blackburn-Munro, G., Garry, E. M., Blakemore, J. A., Dickinson, T., Rosie, R., et al. (2002). A role of the ubiquitin-proteasome system in neuropathic pain. J. Neurosci. : Off. J. Soc. Neurosci. 22, 1363-1372.

Moutal, A., Cai, S., Yu, J., Stratton, H. J., Chefdeville, A., Gomez, K., et al. (2020). Studies on CRMP2 SUMOylation-deficient transgenic mice identify sex-specific $\mathrm{NaV} 1.7$ regulation in the pathogenesis of chronic neuropathic pain. Pain 161, 2629-2651. doi: 10.1097/j.pain.0000000000001951

Moutal, A., Dustrude, E. T., Largent-Milnes, T. M., Vanderah, T. W., Khanna, M., and Khanna, R. (2018). Blocking CRMP2 SUMOylation reverses neuropathic pain. Mol. Psychiatry 23, 2119-2121. doi: 10.1038/mp.2017.117

Moutal, A., White, K. A., Chefdeville, A., Laufmann, R. N., Vitiello, P. F., Feinstein, D., et al. (2019). Dysregulation of CRMP2 post-translational modifications drive its pathological functions. Mol. Neurobiol. 56, 6736-6755. doi: 10.1007/ s12035-019-1568-4

Muley, M. M., Krustev, E., and McDougall, J. J. (2016). Preclinical assessment of inflammatory pain. CNS Neurosci. Therapeutics 22, 88-101. doi: $10.1111 / \mathrm{cns}$. 12486

Nakamura, N. (2018). Ubiquitin system. Int. J. Mol. Sci. 19:1080.

Napetschnig, J., and Wu, H. (2013). Molecular basis of NF-кB signaling. Annu. Rev. Biophys. 42, 443-468. doi: 10.1146/annurev-biophys-083012-130338

Ning, F., Xin, H., Liu, J., Lv, C., Xu, X., Wang, M., et al. (2020). Structure and function of USP5: insight into physiological and pathophysiological roles. Pharmacol. Res. 157:104557. doi: 10.1016/j.phrs.2019.104557

Ossipov, M. H., Bazov, I., Gardell, L. R., Kowal, J., Yakovleva, T., Usynin, I., et al. (2007). Control of chronic pain by the ubiquitin proteasome system in the spinal cord. J. Neurosci. : Off. J. Soc. Neurosci. 27, 8226-8237. doi: 10.1523/ jneurosci.5126-06.2007

Ozaki, T., Matsuoka, J., Tsubota, M., Tomita, S., Sekiguchi, F., Minami, T., et al. (2018). Zinc deficiency promotes cystitis-related bladder pain by enhancing function and expression of $\mathrm{Ca}(\mathrm{v}) 3.2$ in mice. Toxicology 393, 102-112. doi: 10.1016/j.tox.2017.11.012

Pan, Z., Li, G. F., Sun, M. L., Xie, L., Liu, D., Zhang, Q., et al. (2019). MicroRNA1224 Splicing CircularRNA-Filip1l in an Ago2-Dependent manner regulates chronic inflammatory pain via targeting Ubr5. J. Neurosci. : Off. J. Soc. Neurosci. 39, 2125-2143. doi: 10.1523/jneurosci.1631-18.2018
Pickart, C. M. (2001). Mechanisms underlying ubiquitination. Annu. Rev. Biochem. 70, 503-533. doi: 10.1146/annurev.biochem.70.1.503

Pierre, S., Maeurer, C., Coste, O., Becker, W., Schmidtko, A., Holland, S., et al. (2008). Toponomics analysis of functional interactions of the ubiquitin ligase PAM (Protein Associated with Myc) during spinal nociceptive processing. Mol. Cell. Proteomics: MCP. 7, 2475-2485. doi: 10.1074/mcp.m800201-mcp200

Pierre, S., Zhang, D. D., Suo, J., Kern, K., Tarighi, N., and Scholich, K. (2018). Myc binding protein 2 suppresses M2-like phenotypes in macrophages during zymosan-induced inflammation in mice. Eur. J. Immunol. 48, 239-249. doi: 10.1002/eji.201747129

Qiu, S., Li, X. Y., and Zhuo, M. (2011). Post-translational modification of NMDA receptor GluN2B subunit and its roles in chronic pain and memory. Seminars Cell Dev. Biol. 22, 521-529. doi: 10.1016/j.semcdb.2011.06.003

Quan, L., Ishikawa, T., Michiue, T., Li, D. R., Zhao, D., Zhu, B. L., et al. (2005). Quantitative analysis of ubiquitin-immunoreactivity in the midbrain periaqueductal gray matter with regard to the causes of death in forensic autopsy. Legal Med. (Tokyo, Japan) 7, 151-156. doi: 10.1016/j.legalmed.2004. 11.003

Sekiguchi, F., Tsubota, M., and Kawabata, A. (2018). Involvement of voltage-gated calcium channels in inflammation and inflammatory pain. Biol. Pharmaceutical Bull. 41, 1127-1134. doi: 10.1248/bpb.b18-00054

Staub, O., Abriel, H., Plant, P., Ishikawa, T., Kanelis, V., Saleki, R., et al. (2000). Regulation of the epithelial $\mathrm{Na}+$ channel by Nedd4 and ubiquitination. Kidney Int. 57, 809-815. doi: 10.1046/j.1523-1755.2000.00919.x

Stemkowski, P., García-Caballero, A., Gadotti, V. M., M’Dahoma, S., Huang, S., Black, S. A. G., et al. (2016). TRPV1 nociceptor activity initiates USP5/T-type channel-mediated plasticity. Cell Rep. 17, 2901-2912. doi: 10.1016/j.celrep. 2016.11.047

Stemkowski, P. L., Garcia-Caballero, A., Gadotti, V. M., M’Dahoma, S., Chen, L. Souza, I. A., et al. (2017). Identification of interleukin-1 beta as a key mediator in the upregulation of Cav3.2-USP5 interactions in the pain pathway. Mol. Pain 13:1744806917724698.

Stockton, S. D. Jr., Gomes, I., Liu, T., Moraje, C., Hipólito, L., Jones, M. R., et al. (2015). Morphine regulated synaptic networks revealed by integrated proteomics and network analysis. Mol. Cell. Proteomics : MCP. 14, 2564-2576. doi: 10.1074/mcp.m115.047977

Sun, Y. E., Xu, H. Y., Hao, J., Huo, W. W., Qian, Y., and Hou, B. L. (2019). The ubiquitination of spinal MrgC alleviates bone cancer pain and reduces intracellular calcium concentration in spinal neurons in mice. Neurochem. Res. 44, 2527-2535. doi: 10.1007/s11064-019-02869-3

Tai, H. C., and Schuman, E. M. (2008). Ubiquitin, the proteasome and protein degradation in neuronal function and dysfunction. Nat. Rev. Neurosci. 9, 826-838. doi: 10.1038/nrn2499

Tan, F., Thiele, C. J., and Li, Z. (2014). Collapsin response mediator proteins: potential diagnostic and prognostic biomarkers in cancers (Review). Oncol. Lett. 7, 1333-1340. doi: 10.3892/ol.2014.1909

Tomita, S., Sekiguchi, F., Deguchi, T., Miyazaki, T., Ikeda, Y., Tsubota, M., et al. (2019). Critical role of $\mathrm{Ca}(\mathrm{v}) 3.2$ T-type calcium channels in the peripheral neuropathy induced by bortezomib, a proteasome-inhibiting chemotherapeutic agent, in mice. Toxicology 413, 33-39. doi: 10.1016/j.tox.2018.12.003

Treede, R. D., Rief, W., Barke, A., Aziz, Q., Bennett, M. I., Benoliel, R., et al. (2019). Chronic pain as a symptom or a disease: the IASP Classification of Chronic Pain for the International Classification of Diseases (ICD-11). Pain 160, 19-27.

Villarejo-López, L., Jiménez, E., Bartolomé-Martín, D., Zafra, F., Lapunzina, P., Aragón, C., et al. (2017). P2X receptors up-regulate the cell-surface expression of the neuronal glycine transporter GlyT2. Neuropharmacology 125, 99-116. doi: 10.1016/j.neuropharm.2017.07.018

Wang, L., Yin, C., Liu, T., Abdul, M., Zhou, Y., Cao, J. L., et al. (2020). Pellinol regulates neuropathic pain as well as microglial activation through the regulation of MAPK/NF-kappaB signaling in the spinal cord. J. Neuroinflamm. $17: 83$.

Weng, W., Yao, C., Poonit, K., Zhou, X., Sun, C., Zhang, F., et al. (2019). Metformin relieves neuropathic pain after spinal nerve ligation via autophagy flux stimulation. J. Cell. Mol. Med. 23, 1313-1324. doi: 10.1111/ jcmm.14033

Xue, P., Liu, X., Shen, Y., Ju, Y., Lu, X., Zhang, J., et al. (2018). E3 Ubiquitin Ligase $\mathrm{c}$-cbl inhibits microglia activation after chronic 
constriction injury. Neurochem. Res. 43, 1631-1640. doi: 10.1007/s11064-018-2 578-8

Yang, L., Wang, S., Sung, B., Lim, G., and Mao, J. (2008). Morphine induces ubiquitin-proteasome activity and glutamate transporter degradation. J. Biol. Chem. 283, 21703-21713. doi: 10.1074/jbc.m800809200

Yang, Y., He, Y., Wang, X., Liang, Z., He, G., Zhang, P., et al. (2017). Protein SUMOylation modification and its associations with disease. Open Biol. 7:170167. doi: 10.1098/rsob.170167

Yanpallewar, S., Wang, T., Koh, D. C., Quarta, E., Fulgenzi, G., and Tessarollo, L. (2016). Nedd4-2 haploinsufficiency causes hyperactivity and increased sensitivity to inflammatory stimuli. Sci. Rep. 6:32957.

Yi, J. J., and Ehlers, M. D. (2007). Emerging roles for ubiquitin and protein degradation in neuronal function. Pharmacol. Rev. 59, 14-39. doi: 10.1124/pr. 59.1.4

Zavrski, I., Krebbel, H., Wildemann, B., Heider, U., Kaiser, M., Possinger, K., et al. (2005). Proteasome inhibitors abrogate osteoclast differentiation and osteoclast function. Biochem. Biophys. Res. Commun. 333, 200-205. doi: 10.1016/j.bbrc. 2005.05.098

Zhang, Z. Y., Bai, H. H., Guo, Z., Li, H. L., Diao, X. T., Zhang, T. Y., et al. (2020). Ubiquitination and functional modification of GluN2B subunitcontaining NMDA receptors by Cbl-b in the spinal cord dorsal horn. Sci. Signal. 13:eaaw1519. doi: 10.1126/scisignal.aaw1519
Zhang, Z. Y., Bai, H. H., Guo, Z., Li, H. L., He, Y. T., Duan, X. L., et al. (2019a). mGluR5/ERK signaling regulated the phosphorylation and function of glycine receptor $\alpha$ 1ins subunit in spinal dorsal horn of mice. PLoS Biol. 17:e3000371. doi: 10.1371/journal.pbio.3000371

Zhang, Z. Y., Guo, Z., Li, H. L., He, Y. T., Duan, X. L., Suo, Z. W., et al. (2019b). Ubiquitination and inhibition of glycine receptor by HUWE1 in spinal cord dorsal horn. Neuropharmacology 148, 358-365. doi: 10.1016/j.neuropharm. 2019.02.002

Zheng, N., and Shabek, N. (2017). Ubiquitin ligases: structure, function, and regulation. Annu. Rev. Biochem. 86, 129-157. doi: 10.1146/annurev-biochem060815-014922

Conflict of Interest: The authors declare that the research was conducted in the absence of any commercial or financial relationships that could be construed as a potential conflict of interest.

Copyright (c) 2021 Cheng, Deng and Zhou. This is an open-access article distributed under the terms of the Creative Commons Attribution License (CC BY). The use, distribution or reproduction in other forums is permitted, provided the original author(s) and the copyright owner(s) are credited and that the original publication in this journal is cited, in accordance with accepted academic practice. No use, distribution or reproduction is permitted which does not comply with these terms. 